\title{
A meta-analysis comparing the risk of metastases in patients with rectal cancer and MRI-detected extramural vascular invasion (mrEMVl) vs mrEMVI-negative cases
}

Muhammed RS Siddiqui ${ }^{1,2}$, Constantinos Simillis ${ }^{3}$, Chris Hunter ${ }^{1,2}$, Manish Chand ${ }^{1,2}$, Jemma Bhoday ${ }^{1,2}$, Aurelie Garant ${ }^{4}$, Te Vuong ${ }^{4}$, Giovanni Artho ${ }^{4}$, Shahnawaz Rasheed ${ }^{3}$, Paris Tekkis $^{3}$, Al-Mutaz Abulafi ${ }^{1}$ and Gina Brown*,2

${ }^{1}$ Department of Colorectal Surgery, Croydon University Hospital, Croydon CR77YE, UK; ${ }^{2}$ Department of Radiology, Royal Marsden Hospital, Sutton SM2 5PT, UK; ${ }^{3}$ Department of Surgery, Royal Marsden Hospital, Fulham Rd, London SW3 6JJ, UK and ${ }^{4}$ Department of Radiation Oncology, Jewish General Hospital, McGill University, Montreal, QC H3T 1E2, Canada

Background: Pathological extramural vascular invasion (EMVI) is an independent prognostic factor in rectal cancer, but can also be identified on MRI-detected extramural vascular invasion (mrEMVI). We perform a meta-analysis to determine the risk of metastatic disease at presentation and after surgery in mrEMVI-positive patients compared with negative tumours.

Methods: Electronic databases were searched from January 1980 to March 2016. Conventional meta-analytical techniques were used to provide a summative outcome. Quality assessment of the studies was performed.

Results: Six articles reported on mrEMVI in 1262 patients. There were 403 patients in the mrEMVI-positive group and 859 patients in the mrEMVI-negative group. The combined prevalence of mrEMVI-positive tumours was 0.346 (range $=0.198-0.574$ ). Patients with mrEMVI-positive tumours presented more frequently with metastases compared to mrEMVI-negative tumours (fixed effects model: odds ratio $(\mathrm{OR})=5.68,95 \%$ confidence interval $(\mathrm{Cl})(3.75,8.61), z=8.21, \mathrm{df}=2, P<0.001)$. Patients who were mrEMVIpositive developed metastases more frequently during follow-up (random effects model: $\mathrm{OR}=3.91,95 \% \mathrm{Cl}(2.61,5.86), z=6.63$, $d f=5, P<0.001)$.

Conclusions: MRI-detected extramural vascular invasion is prevalent in one-third of patients with rectal cancer. MRI-detected extramural vascular invasion is a poor prognostic factor as evidenced by the five-fold increased rate of synchronous metastases, and almost four-fold ongoing risk of developing metastases in follow-up after surgery.

The link between histopathological extramural vascular invasion (EMVI) in specimens and metastatic disease was first reported in by Brown and Warren (1938) (Gibson et al, 2014). Talbot et al $(1980,1981)$ subsequently showed that tumour spread into 'thickwalled vessels' was evident in almost 52\% of 703 rectal cancer specimens. Follow-up of their series showed a significantly worse 5 -year survival rate and an almost four-fold risk of developing liver metastases (40\%) in patients with EMVI compared to EMVInegative tumours (14\%). The prevalence of EMVI varies greatly and is underreported on histopathological specimens (Quasar Collaborative Group et al, 2007; Messenger et al, 2012). The reasons for this may include lack of specific definitions and inconsistent analysis techniques despite efforts to improve this (Messenger et al, 2011; Kirsch et al, 2013).

*Correspondence: Dr G Brown; E-mail: Gina.Brown@rmh.nhs.uk

Received 19 November 2016; revised 22 February 2017; accepted 21 March 2017; published online 27 April 2017

(C) 2017 Cancer Research UK. All rights reserved 0007-0920/17 
Magnetic resonance imaging is able to demonstrate normal veins within the mesorectum as distinctive low-signal serpiginous structures and when disrupted or expanded by tumour signal, this is strongly linked to the likelihood of pathological EMVI being detected in the specimen. This led to the standardisation of MRIdetected extramural vascular invasion (mrEMVI) definitions in the preoperative assessment of rectal cancer as 'serpiginous extension of tumour signal within a vascular structure - resulting in contiguous or discontinuous expansion of a vein by tumour signal' (Supplementary Figure 1; Brown et al, 2003; Taylor et al, 2008, 2014a; Smith et al, 2008; Shihab et al, 2011; Nougaret et al, 2013; Chand et al, 2014b). By comparing pre and post-treatment scans, magnetic resonance imaging (MRI) identifies the persistence of EMVI in a greater percentage of patients than histopathology (mrEMVI; Chand et al, 2015) and has a high sensitivity even when enhanced histopathological techniques are used (Jhaveri et al, 2016). Several studies have reported the prevalence of mrEMVI and its correlation to the development of metastatic disease (Smith et al, 2008; Hunter et al, 2012; Bugg et al, 2014; Sohn et al, 2014; Seehaus et al, 2015; Chand et al, 2015; Kim et al, 2016). Given the standardised, reproducible and prognostically validated methods of describing tumour using MRI, it is considered a standard for preoperative risk stratification and treatment decision-making (Brown et al, 2003; Ernst-Stecken et al, 2004; Mercury Study Group, 2006; Smith et al, 2008; NICE, 2011; Shihab et al, 2011; Taylor et al, 2011, 2014b; Glimelius et al, 2013; Yu et al, 2014; Battersby et al, 2016; National Comprehensive Cancer Network 2015; Chand et al, 2015). Despite this, patients presenting with the finding of mrEMVI are treated in different ways with a lack of consensus on the use of adjuvant therapy. In a recent survey, only $55 \%$ of surgeons and $57 \%$ of oncologists considered it when deciding on post-operative treatment; this may lead to underestimation of the risks of metastatic disease and the consequent undertreatment of an MRI identified high-risk group (Chand et al, 2014a). Identifying the true overall prevalence of mrEMVI and the risk of metastatic disease will help in establishing the need, or lack thereof, for further treatment strategies and would certainly aid in patient discussions regarding the potential advantages or disadvantages of adjuvant therapy.

This meta-analyses aims to establish the true overall prevalence of rectal tumours with mrEMVI, its association with metastatic disease at the time of presentation and development of distant disease after surgery.

\section{MATERIALS AND METHODS}

Registration and protocol. This meta-analysis was registered on the PROSPERO database a priori with an outline of the proposed hypotheses and analysis (Siddiqui et al, 2015).

Hypothesis. Tumours that are mrEMVI-positive demonstrate a higher incidence of synchronous and metachronous metastases compared with mrEMVI-negative tumours.

Searching and selection. All studies examining the outcomes in patients with rectal cancer and MRI-detected EMVI from January 1980 (first human publications regarding MRI) to July 2016 were identified. The MEDLINE, EMBASE and CINAHL databases available through the United Kingdom's National Health Service National Library of Health website, the Cochrane library and PubMed are available online. Text words 'rectal cancer', 'vascular invasion', 'extramural', 'tumour in vessels', 'medical imaging', 'magnetic resonance', 'MRI' were used in combination with the medical subject heading 'rectal cancers'. Irrelevant articles, reviews and meta-analyses evident from the titles and abstracts were excluded. Relevant articles referenced in these publications were obtained and the references of identified studies were searched to identify any further studies. No language restriction was applied. A flow chart of the literature search according to PRISMA guidelines (Liberati et al, 2009) is shown in Supplementary Figure 2. About 171 articles were screened for relevance. Of the 171 papers initially detected there were 55 duplicates leaving 116 records. Of these 116 records that were screened, most were pathology based and were excluded. Some of the studies were reviews and some studies captured by our search strategy were on unrelated subjects. On further scrutiny six studies comparing outcomes of rectal tumours with and without mrEMVI were found to have useful data for the summative outcome.

Quality assessment. The methodological quality of the trials included for meta-analysis is explained comprehensively in Table 3. Assessment was performed by two authors independently (MRSS and JB; Chalmers et al, 1981; Jadad et al, 1996; Rangel et al, 2003).

Data extraction. Each included article according to our metaanalysis criteria (Supplementary Table 1) was reviewed by two researchers. This was performed independently and if any conflict arose, resolution was through discussion prior to analysis. Only papers examining outcomes in rectal cancer with and without mrEMVI were included. Where more specific data were required the authors of manuscripts were contacted. Our main outcome measures were synchronous and metachronous metastases. For the purposes of this meta-analysis, synchronous metastases were defined as the presence of metastatic disease prior to surgical intervention and metachronous disease was defined as the occurrence of metastases after surgery during the follow-up period.

Data synthesis. Statistical analyses were performed using Comprehensive Meta-Analysis 2006 for Windows XP (Borenstein et al, 2005). A value of $P<0.05$ was chosen as the significance level for outcome measures. Binary data (number of metastases) were summarised as odds ratios (OR) and combined using the MantelHaenszel method (Egger et al, 2006). Heterogeneity of the studies was assessed according to $Q$ and $I^{2}$. A random and fixed effects method was used. Studies were excluded on an individual basis to assess for influence on heterogeneity. In a sensitivity analysis, 1 was added to each cell frequency for trials in which no event occurred, according to the method recommended by Deeks et al (2001). Forest plots were used for the graphical display.

\section{RESULTS}

Six articles (Smith et al, 2008; Hunter et al, 2012; Bugg et al, 2014; Sohn et al, 2014; Seehaus et al, 2015; Chand et al, 2015) reporting on metastatic disease in patients with rectal cancer and EMVI that were retrieved from the electronic databases met the inclusion criteria (Supplementary Table 1). Two studies were from the same centre but evaluated different time cohorts (Smith et al, 2008; Chand et al, 2015). One study included a combination of synchronous and metachronous metastases (predominately synchronous), and was included in the analyses for both outcome measures; exclusion of this study did not alter the significance for both synchronous or metachronous metastases (Sohn et al, 2014). For one study, the mrEMVI status in a cohort of patients was obtained after contacting the authors (Hunter et al, 2012). A further study evaluated persistent ymrEMVI status after preoperative chemoradiotherapy (Chand et al, 2015). Characteristics of each article are given in Tables 1 and 2 . The methodological quality of the trials included for meta-analysis is shown in Table 3 (Chalmers et al, 1981; Jadad et al, 1996; Rangel et al, 2003).

Prevalence of MRI defined EMVI-positive rectal tumours. The combined prevalence of mrEMVI-positive tumours from the six studies (Smith et al, 2008; Hunter et al, 2012; Bugg et al, 2014; 
Table 1. Outcome measures

\begin{tabular}{|c|c|c|c|c|c|c|}
\hline & $\begin{array}{c}\text { Smith et al, } \\
2008\end{array}$ & $\begin{array}{c}\text { Hunter et al, } \\
2012\end{array}$ & $\begin{array}{c}\text { Bugg et al, } \\
2014\end{array}$ & $\begin{array}{l}\text { Sohn et al, } \\
\quad 2014\end{array}$ & $\begin{array}{c}\text { Chand et al, } \\
2015\end{array}$ & $\begin{array}{c}\text { Seehaus et al, } \\
2015\end{array}$ \\
\hline \multicolumn{7}{|l|}{ Patients ( $n$ ) } \\
\hline EMVI+ & 24 & 90 & 53 & 98 & 99 & 39 \\
\hline \multicolumn{7}{|c|}{ Number with metachronous metastases } \\
\hline $\mathrm{EMVI}+$ & 18 & 35 & 13 & $42^{\mathrm{a}}$ & 36 & 15 \\
\hline EMVI - & 41 & 18 & 10 & $37^{a}$ & 14 & 5 \\
\hline $\mathrm{EMVI}+$ & ND & ND & ND & ND & 5 & ND \\
\hline EMVI - & ND & ND & ND & ND & 3 & ND \\
\hline \multicolumn{7}{|c|}{ Disease/recurrence-free survival ( 3 yr) } \\
\hline $\mathrm{EMVI}+$ & $35 \%$ (s.d. $=9.75)$ & ND & ND & ND & $42.7 \%$ (s.d. $=12.95$ ) & ND \\
\hline EMVI - & $74.1 \%$ (s.d. $=4.53$ ) & ND & ND & ND & $79.2 \%$ (s.d. $=4.6$ ) & ND \\
\hline \multicolumn{7}{|c|}{ Number with synchronous metastases } \\
\hline EMVI - (lung/liver/multi/other) & ND & $1 / 6 / 11 / 0$ & ND & ND & $7 / 1 / 2 / 4$ & ND/5/ND/ND \\
\hline \multicolumn{7}{|c|}{ Site of synchronous metastases } \\
\hline EMVI + (lung/liver/multi/other) & ND & $2 / 12 / 3 / 4$ & ND & ND & ND & ND \\
\hline EMVI - (lung/liver/multi/other) & ND & $4 / 4 / 2 / 1$ & ND & ND & ND & ND \\
\hline
\end{tabular}

Table 2. Characteristics of studies comparing patients with and without EMVI

\begin{tabular}{|c|c|c|c|c|c|c|}
\hline & $\begin{array}{c}\text { Smith et al, } \\
2008\end{array}$ & $\begin{array}{l}\text { Hunter et al, } \\
2012\end{array}$ & $\begin{array}{l}\text { Bugg et al, } \\
2014\end{array}$ & $\begin{array}{l}\text { Sohn et al, } \\
\quad 2014\end{array}$ & $\begin{array}{c}\text { Chand et al, } \\
2015\end{array}$ & $\begin{array}{l}\text { Seehaus et al, } \\
2015\end{array}$ \\
\hline Total number of patients $(n)$ & 121 & 236 & 202 & 447 & 188 & 68 \\
\hline Gender ( $\mathrm{m}: \mathrm{f})$ & $77: 65$ & $161: 69(N D=6)$ & $123: 79$ & $291: 156$ & $121: 67$ & $44: 24$ \\
\hline $\begin{array}{l}\text { Tumour (MRI) } \\
\text { T-stage } \\
\text { Node positive } \\
\text { CRM positive } \\
\text { Height }\end{array}$ & $\begin{array}{l}\text { T3 } \\
\text { ND } \\
\text { ND } \\
\text { ND }\end{array}$ & 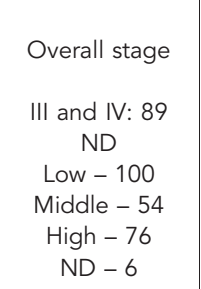 & $\begin{array}{l}\text { ND } \\
\text { ND } \\
\text { ND } \\
\text { ND }\end{array}$ & $\begin{array}{c}\text { T3 } \\
286 \\
75 \\
\text { Below peritoneal } \\
\text { Reflection - 259 } \\
\text { Above peritoneal } \\
\text { Reflection - } 61\end{array}$ & $\begin{array}{c}137 \text { (Defined as } \\
>3 c \text { ) } \\
123 \\
81 \\
\text { Low }-69 \\
\text { Middle }-62 \\
\text { High }-7\end{array}$ & $\begin{array}{c}\text { T3 } \\
\text { ND } \\
\text { ND } \\
\text { Low }-32 \\
\text { Middle }-36 \\
\text { High }-0\end{array}$ \\
\hline $\begin{array}{l}\text { Neoadjuvant/adjuvant } \\
\text { therapy }\end{array}$ & $+1+(\mathrm{M})$ & $+1-$ & Primary surgery only & Primary surgery/ + (M) & $+1+$ & ND/ND \\
\hline
\end{tabular}

Sohn et al, 2014; Seehaus et al, 2015; Chand et al, 2015) was 0.346 (confidence interval $(\mathrm{CI})=0.237-0.474$ ) and is graphically portrayed in Figure 1.

Synchronous metastases. Three studies incorporating a total of 804 patients (Smith et al, 2008; Hunter et al, 2012; Sohn et al, 2014) contributed towards a summative outcome. Seventy patients had metastases out of 212 patients with mrEMVI (33\%). Fifty-two patients presented with metastases out of 592 patients without mrEMVI (9\%).
Patients with mrEMVI-positive tumours presented more frequently with metastases at presentation compared to mrEMVI-negative tumours (fixed effects model: odds ratio $(\mathrm{OR})=5.68,95 \% \mathrm{CI}(3.75$, $8.61), \quad z=8.21, \quad P<0.001$; Figure 2). There was no significant heterogeneity among trials $\left(Q=1.85, \mathrm{df}=2, P=0.40, I^{2}=0\right)$ and the fixed effects model was used.

In a sensitivity analysis, one study was excluded (Sohn et al, 2014) due to clinical heterogeneity (inclusion of synchronous and metachronous metastases) although the heterogeneity was not reduced and the outcome remained significant (fixed effects model: 
Table 3. Methodological qualities of comparative studies included (adapted from the Scottish Intercollegiate Guidelines National Comprehensive Cancer Network, 2015 and Rangel et al, 2003)

\begin{tabular}{|c|c|c|c|c|c|c|}
\hline Quality measures & $\begin{array}{c}\text { Smith et al, } \\
2008\end{array}$ & $\begin{array}{c}\text { Hunter et al, } \\
2012\end{array}$ & $\begin{array}{l}\text { Bugg et al, } \\
2014\end{array}$ & $\begin{array}{l}\text { Sohn et al, } \\
2014\end{array}$ & $\begin{array}{c}\text { Chand et al, } \\
2015\end{array}$ & $\begin{array}{l}\text { Seehaus } \\
\text { et al, } 2015\end{array}$ \\
\hline Inclusion criteria & 1 & 1 & 1 & 1 & 1 & 0.5 \\
\hline Exclusion criteria & 1 & 1 & 1 & 1 & 1 & 1 \\
\hline Can the number of participating centres be determined & 1 & 1 & 1 & 1 & 1 & 1 \\
\hline Can the number of radiologists who participated be determined & 0 & 0 & 0 & 0 & 0 & 1 \\
\hline $\begin{array}{l}\text { Can the reader determine where the authors are on the learning } \\
\text { curve for the reported procedure }\end{array}$ & 0 & 0 & 0 & 0 & 0 & 1 \\
\hline Are diagnostic criteria clearly stated for clinical outcomes if required & 1 & 1 & 1 & 0 & 1 & 1 \\
\hline $\begin{array}{l}\text { Is there any way that they have tried to standardise the radiological } \\
\text { interpretation }\end{array}$ & 1 & 1 & 1 & 0 & 1 & 1 \\
\hline Do authors address whether there is any missing data & 1 & 1 & 1 & 1 & 1 & 1 \\
\hline Were patients in each group treated along similar timelines & 1 & 1 & 1 & 1 & 1 & 1 \\
\hline Outcomes clearly defined? & 1 & 1 & 1 & 0 & 1 & 1 \\
\hline
\end{tabular}

$\mathrm{OR}=4.60,95 \% \mathrm{CI}(2.34,9.07), z=4.41, P<0.001)$. Thus patients with mrEMVI were over four times more likely to present with metastases compared to patients without mrEMVI.

Metachronous metastases. Six studies incorporating 1262 patients (Stewart et al, 2007; Smith et al, 2008; Hunter et al, 2012; Bugg et al, 2014; Sohn et al, 2014; Chand et al, 2015) contributed towards a summative outcome. About 159 out of 403 patients had metastases and were mrEMVI-positive (39\%). About 125 out of 859 patients had metastases and were mrEMVI-negative (15\%).

Patients who had mrEMVI-positive tumours more often had metastases during follow-up compared with mrEMVI-negative tumours (fixed effects model: $\mathrm{OR}=4.02,95 \%$ CI $(2.99,5.39$ ), $z=9.26, \quad P<0.001$; random effects model: OR $=3.91,95 \% \mathrm{CI}$ (2.61, 5.86), $z=6.63, P<0.001$; Figure 3$)$. There was no significant heterogeneity among trials $\left(Q=8.53, \mathrm{df}=5, P=0.129, I^{2}=41\right)$, and the fixed and random effects models were used.

One study was excluded (Sohn et al, 2014) due to clinical heterogeneity (inclusion of synchronous and metachronous metastases) and heterogeneity was reduced $(Q=4.35, \mathrm{df}=5$, $P=0.36, I^{2}=8$ ), but the outcome remained significant (fixed effects model: $\mathrm{OR}=3.26,95 \% \mathrm{CI}(2.29,4.66), z=4.35, P<0.001)$. Therefore patients with mrEMVI, over three times, more likely to develop metastases than mrEMVI-negative tumours.

\section{DISCUSSION}

The present analysis has shown that mrEMVI indicates poorer disease-free survival (DFS) (Chand et al, 2014b). Thus, identifying the burden of disease in the population and its almost four-fold increased risk of further metastatic disease may in future influence the use of neoadjuvant and adjuvant treatment strategies and certainly warrants future trial designs that take into account the presence of mrEMVI as a risk factor.

Main findings. This analysis of 804 patients has shown that those with mrEMVI are five times more likely to have metastases at presentation compared to those without. Analysis of 1262 with mrEMVI-positive tumours is almost four times more likely to develop metastases on follow-up. The meta-analysis has also shown that MRI-detected prevalence of EMVI in rectal cancer is 34.6\% (CI: $23.7-47.4 \%$ ) and thus amounts to over a third of all rectal cancers. Although the link between pathological EMVI and liver metastases is well-established (Talbot et al, 1980), its reporting by individual pathologists is highly variable with documented pathological underreporting of pEMVI resulting in rates of only 9-21\% in published audits (Stewart et al, 2007; Courtney et al, 2009; Messenger et al, 2011, 2012; Betge et al, 2012; Bhangu et al, 2013; Kirsch et al, 2013; Gibson et al, 2014). Furthermore pathological EMVI status is only available after surgery, thus limiting the ability to tailor preoperative therapy. Arguably, MRI assessment of EMVI can be justified as a gold standard as it has both a higher detection rate and represents an independent risk factor for recurrence.

Importance and clinical implications. MRI-detected extramural vascular invasion-positive tumours represent a large cohort (34.6\%) within the rectal cancer population and carry a significantly high risk of metastatic disease. Its positive identification could lead to better surveillance of high-risk patients as well as future improvements in therapeutic strategies (Hunter et al, 2012; Slesser et al, 2015). This analysis has quantified the metastatic risk at presentation and after surgery following analysis of more than 800 patients who were identified as mrEMVI-positive thus enabling important prognostic information from the preoperative MRI assessment to be shared with patients. This is relevant because the current TNM classification and treatment policies largely fail to account for this prognostic group (Bujko et al, 2010). Existing recommendations for patients with pEMVI are based on historical studies, which were limited by the low prevalence and underreporting of EMVI or misreporting vascular tumour deposits as 'lymph nodes' (Ueno et al, 2007, 2012). Node negative tumours in such studies showed a far greater overall survival and DFS rates than those currently observed in mrEMVI-positive node negative tumours (Quasar Collaborative Group et al, 2007). The potential benefit of adjuvant chemotherapy in this previously unidentified group consequently remains uncertain (Quasar Collaborative Group et al, 2007). The risk of metastatic disease associated with mrEMVI has implications for administration of long-course chemoradiotherapy (LCRT) with additional preoperative chemotherapy given either before or after LCRT, and this is currently under investigation in a number of clinical trials (Courtney et al, 2009; Nilsson et al, 2013; Slesser et al, 2015).

Appraisal of evidence and heterogeneity. The overall incidence of mrEMVI in the individual studies was similar except for two studies that showed a prevalence of 53 (Chand et al, 2015) and $57 \%$ (Seehaus et al, 2015). One of these studies evaluated a population limited to advanced rectal tumours undergoing preoperative chemoradiotherapy, which accounts for the higher 
Study name

$\begin{array}{lccc} & \begin{array}{c}\text { Event } \\ \text { rate }\end{array} & \begin{array}{c}\text { Lower } \\ \text { limit }\end{array} & \begin{array}{c}\text { Upper } \\ \text { limit }\end{array} \\ \text { Smith et al 2008 } & 0.198 & 0.137 & 0.279 \\ \text { Hunter et al 2012 } & 0.381 & 0.322 & 0.445 \\ \text { Bugg et al 2014 } & 0.262 & 0.206 & 0.327 \\ \text { Sohn et al 2014 } & 0.219 & 0.183 & 0.260 \\ \text { Chand et al 2015 } & 0.527 & 0.455 & 0.597 \\ \text { Seehaus et al 2015 } & 0.574 & 0.454 & 0.685 \\ & 0.346 & 0.237 & 0.474\end{array}$

Event rate and $95 \% \mathrm{Cl}$

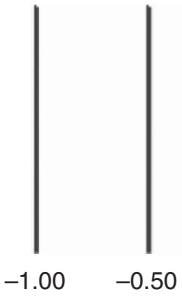

Figure 1. The proportion of patients with rectal cancer who have extramural vascular invasion identified on MRI at the time of presentation.

Study name

$\begin{array}{lrrr} & \begin{array}{c}\text { Odds } \\ \text { ratio }\end{array} & \begin{array}{c}\text { Lower } \\ \text { limit }\end{array} & \begin{array}{c}\text { Upper } \\ \text { limit }\end{array} \\ \text { Smith et al 2008 } & 9.574 & 2.525 & 36.300 \\ \text { Hunter et al 2012 } & 3.735 & 1.704 & 8.189 \\ \text { Sohn et al2014 } & 6.324 & 3.739 & 10.697 \\ & 5.683 & 3.753 & 8.606\end{array}$

Odds ratio and $95 \% \mathrm{Cl}$
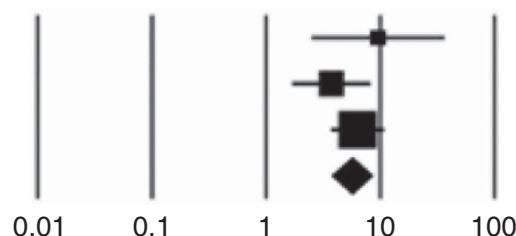

Figure 2. The proportion of patients with metastases at the time of presentation who have mrEMVI-positive tumours vs mrEMVI-negative tumours.

$\begin{array}{lccr}\underline{\text { Study name }} & & & \\ & \begin{array}{c}\text { Odds } \\ \text { ratio }\end{array} & \begin{array}{c}\text { Lower } \\ \text { limit }\end{array} & \begin{array}{c}\text { Upper } \\ \text { limit }\end{array} \\ \text { Smith et al 2008 } & 4.098 & 1.495 & 11.227 \\ \text { Hunter et al 2012 } & 4.525 & 2.361 & 8.672 \\ \text { Bugg et al 2014 } & 4.518 & 1.844 & 11.070 \\ \text { Sohn et al2014 } & 6.324 & 3.739 & 10.697 \\ \text { Chand et al 2015 } & 1.945 & 1.045 & 3.622 \\ \text { Seehaus et al 2015 } & 3.000 & 0.941 & 9.565 \\ & 4.016 & 2.992 & 5.390\end{array}$
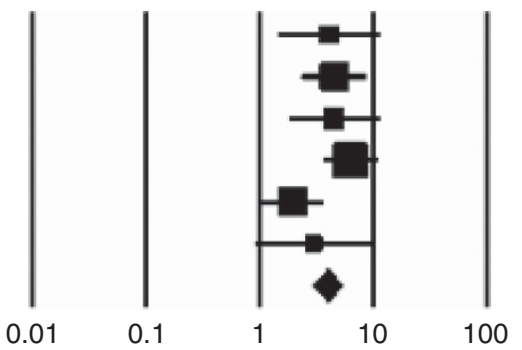

Figure 3. The proportion of patients who develop metastases after surgery who had mrEMVI-positive tumours before surgery vs mrEMVInegative tumours before surgery.

prevalence (Chand et al, 2015). The other studies included both earlier and locally advanced stage tumours (Smith et al, 2008; Sohn et al, 2014; Thomson et al, 2015). In this meta-analysis, one study included only mrEMVI-positive patients at baseline and compared patients who were persistently positive with EMVI that regressed. In this paper, those tumours that regressed to ymrEMVI-negative had similar low rates of metastatic disease as those who are mrEMVI-negative on baseline scans (Chand et al, 2015). The link betweeen mrEMVI and metastatic disease has been further highlighted by studies showing that about $90 \%$ of patients with hepatic metastases are EMVI-positive (Slesser et al, 2015). One limitation of this analysis is that the cohorts may not be truly comparable due to tumour-related factors; however most of our results did not identify significant heterogeneity between studies for the outcomes of interest, suggesting the cohorts are comparable. In the results where there was significant heterogeneity (clinical or statistical), it sets the stage for further research to identify the reasons for variability and inconsistency between studies. This meta-analysis has more power than individual studies to identify a true difference that exists between two groups, especially for outcomes that require larger sample sizes. In addition, our meta-analysis not only has more power to identify statistical difference, but also increases the precision in estimating the size of the effects of difference between the groups.

Quality assessment and limitations. Quality assessment of the studies (retrospective reviews of databases) included in this metaanalysis is shown in Table 3. It is too early to comment on publication bias.

The individual articles in our studies showed clinical heterogeneity when examining metastatic disease after surgery and this may be due to differing follow-up times. One study included 
synchronous and metachronous metastases (Sohn et al, 2014) and when excluded from our analysis reduced the heterogeneity. Some studies (such as Smith et al, 2008) included in our meta-analysis had small sample sizes that resulted in wide CIs and caution should be used when drawing conclusions. Despite the lack of statistical heterogeneity, the clinical differences need to be borne in mind as well as the relatively small number of patients retrieved from the literature. The small numbers involved also has the potential for overestimating the ORs of our overall outcome results and, therefore, although our results are strongly supportive of our conclusions, caution should be maintained and further trials would certainly be warranted. One potential area is that of tumourrelated factors, which may affect the results; however all the preoperative variables assessed were comparable in the studies and while contributing to heterogeneity and to some extent the overall ORs, it is unlikely to affect the direction of the result. The MERCURY II study has also shown that nodal status did not predict for local or distant failure, in addition the mrEMVI positivity rate was greater than the CRM-positive rate therefore making mrEMVI likely to be a more predictive factor (Battersby et al, 2016). Further studies should standardise follow-up of cases to add further to the literature.

Future studies. Further prospective matched cohort studies focusing on outcomes will help in risk stratification of mrEMVIpositive tumours. The clear definitions of EMVI identified on MRI, and confirmed in this meta-analysis, means that this imaging modality should be adopted as the gold standard in the assessment of this prognostic factor. This analysis has shown that mrEMVI is a likely precursor to metastatic disease and will be formally tested in a prospective study. With its greater detection of patients who are at high risk of developing metastatic disease than current methods, treatment with systemic chemotherapy may, in future, reduce the risk of recurrent disease. Further research into the biological processes of development of metastases and mrEMVI may be facilitated by study into release of tumour cells and DNA into the circulation (Talbot et al, 1981).

\section{CONCLUSION}

Extramural vascular invasion is a poor prognostic factor in rectal cancer. It is now readily identified on MRI as an independent prognostic factor with a significant prevalence in rectal tumour population. This meta-analysis has shown that patients with mrEMVI-positive tumours are over five times more likely to have synchronous metastases and over three times as likely to develop metastases after surgery.

\section{ACKNOWLEDGEMENTS}

This project was supported by the National Institute for Health Research RM/ICR Biomedical Research Centre and Lisa Scerri, and McGill University and Hospital for access to raw data.

\section{CONFLICT OF INTEREST}

The authors declare no conflict of interest.

\section{REFERENCES}

Battersby NJ, How P, Moran B, Stelzner S, West NP, Branagan G, Strassburg J, Quirke P, Tekkis P, Pedersen BG, Gudgeon M, Heald B, Brown G, Group, MIS (2016) Prospective validation of a low rectal cancer magnetic resonance imaging staging system and development of a local recurrence risk stratification model: The MERCURY II Study. Ann Surg 263:

751-760.

Betge J, Pollheimer MJ, Lindtner RA, Kornprat P, Schlemmer A, Rehak P, Vieth M, Hoefler G, Langner C (2012) Intramural and extramural vascular invasion in colorectal cancer: prognostic significance and quality of pathology reporting. Cancer 118: 628-638.

Bhangu A, Fitzgerald JE, Slesser A, Northover JM, Faiz O, Tekkis P (2013) Prognostic significance of extramural vascular invasion in T4 rectal cancer. Colorectal Dis 15: e665-e671.

Borenstein M, HL, Higgins J, Rothstein H (ed.) (2005) ComprehensiveMetaanalysis Version 2. Englewood, NJ, USA.

Brown CE, Warren S (1938) Visceral metastasis from rectal carcinoma. Surg Gynecol Obstet 66: 611-621.

Brown G, Radcliffe AG, Newcombe RG, Dallimore NS, Bourne MW, Williams GT (2003) Preoperative assessment of prognostic factors in rectal cancer using high-resolution magnetic resonance imaging. Br J Surg 90: 355-364.

Bugg WG, Andreou AK, Biswas D, Toms AP, Williams SM (2014) The prognostic significance of MRI-detected extramural venous invasion in rectal carcinoma. Clin Radiol 69: 619-623.

Bujko K, Glynne-Jones R, Bujko M (2010) Does adjuvant fluoropyrimidinebased chemotherapy provide a benefit for patients with resected rectal cancer who have already received neoadjuvant radiochemotherapy? A systematic review of randomised trials. Ann Oncol 21: 1743-1750.

Chalmers TC, Smith Jr H, Blackburn B, Silverman B, Schroeder B, Reitman D, Ambroz A (1981) A method for assessing the quality of a randomized control trial. Control Clin Trials 2: 31-49.

Chand M, Evans J, Swift RI, Tekkis PP, West NP, Stamp G, Heald RJ, Brown G (2015) The prognostic significance of postchemoradiotherapy high-resolution MRI and histopathology detected extramural venous invasion in rectal cancer. Ann Surg 261: 473-479.

Chand M, Swift RI, Chau I, Heald RJ, Tekkis PP, Brown G (2014a) Adjuvant therapy decisions based on magnetic resonance imaging of extramural venous invasion and other prognostic factors in colorectal cancer. Ann $R$ Coll Surg Engl 96: 543-546.

Chand M, Swift RI, Tekkis PP, Chau I, Brown G (2014b) Extramural venous invasion is a potential imaging predictive biomarker of neoadjuvant treatment in rectal cancer. Br I Cancer 110: 19-25.

Courtney ED, West NJ, Kaur C, Ho J, Kalber B, Hagger R, Finlayson C, Leicester RJ (2009) Extramural vascular invasion is an adverse prognostic indicator of survival in patients with colorectal cancer. Colorectal Dis 11: $150-156$.

Deeks JJ, Altman DG, Bradburn MJ (2001) Statistical methods for examining heterogeneity and combining results from several studies in meta-analysis. In: Systematic Reviews in Health Care: Meta-Analysis in Context, Group, BP (ed.) 2nd edn. BMJ Publication group: London.

Egger M, Smith GD, Altman DG (2006) Systematic Reviews in Healthcare. BMJ Publishing: London.

Ernst-Stecken A, Grabenbauer G, Iro H, Plasswilm L, Sauer R (2004) Phase II trial of hyperfractionated accelerated split-course radiochemotherapy with 5-FU and Cis-DDP in advanced head and neck cancer: results and toxicity. Strahlenther Onkol 180: 805-810.

Gibson KM, Chan C, Chapuis PH, Dent OF, Bokey L (2014) Mural and extramural venous invasion and prognosis in colorectal cancer. Dis Colon Rectum 57: 916-926.

Glimelius B, Tiret E, Cervantes A, Arnold D. Group, EGW (2013) Rectal cancer: ESMO Clinical Practice Guidelines for diagnosis, treatment and follow-up. Ann Oncol 24(Suppl 6): vi81-vi88.

Hunter CJ, Garant A, Vuong T, Artho G, Lisbona R, Tekkis P, Abulafi M, Brown G (2012) Adverse features on rectal MRI identify a high-risk group that may benefit from more intensive preoperative staging and treatment. Ann Surg Oncol 19: 1199-1205.

Jadad AR, Moore RA, Carroll D, Jenkinson C, Reynolds DJ, Gavaghan DJ, Mcquay HJ (1996) Assessing the quality of reports of randomized clinical trials: is blinding necessary? Control Clin Trials 17: 1-12.

Jhaveri KS, Hosseini-Nik H, Thipphavong S, Assarzadegan N, Menezes RJ, Kennedy ED, Kirsch R (2016) MRI detection of extramural venous invasion in rectal cancer: correlation with histopathology using elastin stain. AJR Am J Roentgenol 206: 747-755.

Kim H, Myoung S, Koom WS, Kim NK, Kim MJ, Ahn JB, Hur H, Lim JS (2016) MRI risk stratification for tumor relapse in rectal cancer achieving 
pathological complete remission after neoadjuvant chemoradiation therapy and curative resection. PLoS One 11: e0146235.

Kirsch R, Messenger DE, Riddell RH, Pollett A, Cook M, Al-Haddad S, Streutker CJ, Divaris DX, Pandit R, Newell KJ, Liu J, Price RG, Smith S, Parfitt JR, Driman DK (2013) Venous invasion in colorectal cancer: impact of an elastin stain on detection and interobserver agreement among gastrointestinal and nongastrointestinal pathologists. Am J Surg Pathol 37: $200-210$.

Liberati A, Altman DG, Tetzlaff J, Mulrow C, Gotzsche PC, Ioannidis JP, Clarke M, Devereaux PJ, Kleijnen J, Moher D (2009) The PRISMA statement for reporting systematic reviews and meta-analyses of studies that evaluate healthcare interventions: explanation and elaboration. BMJ 339: b2700.

Mercury Study Group (2006) Diagnostic accuracy of preoperative magnetic resonance imaging in predicting curative resection of rectal cancer: prospective observational study. BMJ 333: 779.

Messenger DE, Driman DK, Kirsch R (2012) Developments in the assessment of venous invasion in colorectal cancer: implications for future practice and patient outcome. Hum Pathol 43: 965-973.

Messenger DE, Driman DK, Mcleod RS, Riddell RH, Kirsch R (2011) Current practice patterns among pathologists in the assessment of venous invasion in colorectal cancer. J Clin Pathol 64: 983-989.

Molecular, Pathologic and MRI Investigation of the Prognostic and Redictive Importance of Extramural Venous Invasion in Rectal Cancer (MARVEL) Trial Protocol. Available at: https://clinicaltrials.gov/ct2/show/ NCT01995942 Accessed on 17 August 2016.

National Institute of Clinical Excellence (2011) UK NICE guidelines. Available at: http://www.nice.org.uk/guidance/cg131/chapter/1-recommendations.

National Comprehensive Cancer Network (2015) NCCN Clinical Practice Guidelines in Oncology: Rectal Cancer. V.3.2015. Available at: www.nccn.org/ professionals/physician_gls/pdf/rectal.pdf Accessed on 27 January 2016.

NICE (2011) Colorectal Cancer: Diagnosis and Management. NICE Colorectal Cancer: Diagnosis and Management. Available at: https://www.nice.org.uk/ guidance/cg131/resources/colorectal-cancer-diagnosis-and-management35109505330117

Nilsson PJ, Van Etten B, Hospers GA, Pahlman L, Van De Velde CJ, Beets-Tan RG, Blomqvist L, Beukema JC, Kapiteijn E, Marijnen CA, Nagtegaal ID, Wiggers T, Glimelius B (2013) Short-course radiotherapy followed by neo-adjuvant chemotherapy in locally advanced rectal cancerthe RAPIDO trial. BMC Cancer 13: 279.

Nougaret S, Reinhold C, Mikhael HW, Rouanet P, Bibeau F, Brown G (2013) The use of MR imaging in treatment planning for patients with rectal carcinoma: have you checked the 'DISTANCE'? Radiology 268: 330-344.

Quasar Collaborative Group, Gray R, Barnwell J, Mcconkey C, Hills RK, Williams NS, Kerr DJ (2007) Adjuvant chemotherapy versus observation in patients with colorectal cancer: a randomised study. Lancet 370: 2020-2029.

Rangel SJ, Kelsey J, Colby CE, Anderson J, Moss RL (2003) Development of a quality assessment scale for retrospective clinical studies in pediatric surgery. J Pediatr Surg 38: 390-396, discussion 390-396.

Seehaus A, Vaccaro C, Quadrelli M, Calvo M, Rossi G, Savluk L, Pablo Santino J, Ojea Quintana G, García Mónaco R (2015) Magnetic resonance and extramural vascular invasion in patients with rectal cancer and liver metastases. Acta Gastroenterol Latinoam 45: 31-36.

Shihab OC, Taylor F, Salerno G, Heald RJ, Quirke P, Moran BJ, Brown G (2011) MRI predictive factors for long-term outcomes of low rectal tumours. Ann Surg Oncol 18: 3278-3284.

Siddiqui M, Chand M, Bhoday J, Tekkis P, Abulafi AM, Brown G (2015) Correlation between MRI Detected Extra-Mural Vascular Invasion (mrEMVI) in Rectal Cancer and Metastatic Disease: a Meta-Analysis. PROSPERO 2015:CRD42015027923. Available at: http://www.crd.york. ac.uk/PROSPERO/display_record.asp?ID=CRD42015027923.

Slesser AA, Khan F, Chau I, Khan AZ, Mudan S, Tekkis PP, Brown G, Rao S (2015) The effect of a primary tumour resection on the progression of synchronous colorectal liver metastases: an exploratory study. Eur J Surg Oncol 41: 484-492.
Smith NJ, Barbachano Y, Norman AR, Swift RI, Abulafi AM, Brown G (2008) Prognostic significance of magnetic resonance imagingdetected extramural vascular invasion in rectal cancer. Br J Surg 95: 229-236.

Sohn B, Lim JS, Kim H, Myoung S, Choi J, Kim NK, Kim MJ (2014) MRIdetected extramural vascular invasion is an independent prognostic factor for synchronous metastasis in patients with rectal cancer. Eur Radiol 25: 1347-1355.

Stewart CJ, Morris M, De Boer B, Iacopetta B (2007) Identification of serosal invasion and extramural venous invasion on review of Dukes' stage $B$ colonic carcinomas and correlation with survival. Histopathology 51: 372-378.

Talbot IC, Ritchie S, Leighton MH, Hughes AO, Bussey HJ, Morson BC (1980) The clinical significance of invasion of veins by rectal cancer. Br J Surg 67: 439-442.

Talbot IC, Ritchie S, Leighton MH, Hughes AO, Bussey HJ, Morson BC (1981) Spread of rectal cancer within veins. Histologic features and clinical significance. Am J Surg 141: 15-17.

Taylor FG, Quirke P, Heald RJ, Moran B, Blomqvist L, Swift I, Sebag-Montefiore DJ, Tekkis P, Brown G, Group, MS (2011) Preoperative high-resolution magnetic resonance imaging can identify good prognosis stage I, II, and III rectal cancer best managed by surgery alone: a prospective, multicenter, European study. Ann Surg 253: 711-719.

Taylor FG, Quirke P, Heald RJ, Moran BJ, Blomqvist L, Swift IR, Sebag-Montefiore D, Tekkis P, Brown G, Magnetic Resonance Imaging in Rectal Cancer European Equivalence Study, G (2014a) Preoperative magnetic resonance imaging assessment of circumferential resection margin predicts disease-free survival and local recurrence: 5-year follow-up results of the MERCURY study. J Clin Oncol 32: $34-43$.

Taylor FGM, Quirke P, Heald RJ, Moran BJ, Blomqvist L, Swift IR, Sebag-Montefiore D, Tekkis P, Brown G (2014b) Preoperative magnetic resonance imaging assessment of circumferential resection margin predicts disease-free survival and local recurrence: 5-year follow-up results of the MERCURY Study. J Clin Oncol 32: 34-U114.

Taylor FGM, Swift RI, Blomqvist L, Brown G (2008) A systematic approach to the interpretation of preoperative staging MRI for rectal cancer. AJR Am J Roentgenol 191: 1827-1835.

Thomson E, Scott N, Tolan D (2015) Re: the prognostic significance of MRI-detected extramural venous invasion in rectal carcinoma. Clin Radiol 70: 111-112.

Ueno H, Mochizuki H, Hashiguchi Y, Ishiguro M, Miyoshi M, Kajiwara Y, Sato T, Shimazaki H, Hase K (2007) Extramural cancer deposits without nodal structure in colorectal cancer: optimal categorization for prognostic staging. Am J Clin Pathol 127: 287-294.

Ueno H, Mochizuki H, Shirouzu K, Kusumi T, Yamada K, Ikegami M, Kawachi H, Kameoka S, Ohkura Y, Masaki T, Kushima R, Takahashi K, Ajioka Y, Hase K, Ochiai A, Wada R, Iwaya K, Nakamura T, Sugihara K, Study Group for Tumor Deposits Without Lymph Node Structure in Colorectal Cancer Projected by The Japanese Society for Cancer of the ColonRectum (2012) Multicenter study for optimal categorization of extramural tumor deposits for colorectal cancer staging. Ann Surg 255: 739-746.

Yu SKT, Chand M, Tait DM, Brown GJ (2014) Magnetic resonance imaging defined mucinous rectal carcinoma is an independent imaging biomarker for poor prognosis and poor response to preoperative chemoradiotherapy. Eur J Cancer 50: 920-927.

This work is published under the standard license to publish agreement. After 12 months the work will become freely available and the license terms will switch to a Creative Commons AttributionNonCommercial-Share Alike 4.0 Unported License. 